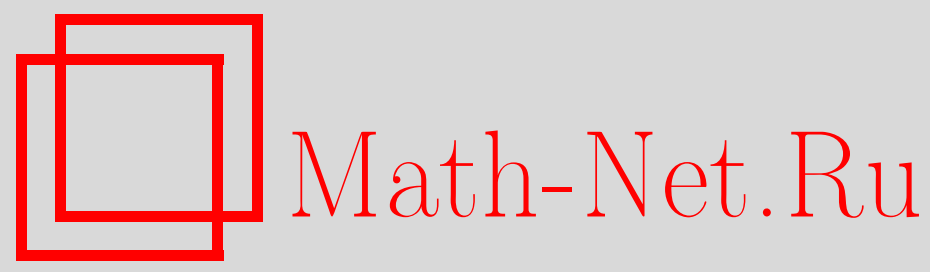

М. Г. Крейнес, Е. М. Крейнес, Матричные модели текстов. Интерпретация моделей и экспериментальная верификация, Матем. моделирование, 2020, том 32, номер 7, 24-46

DOI: https://doi.org/10.20948/mm-2020-07-02

Использование Общероссийского математического портала Math-Net.Ru подразумевает, что вы прочитали и согласны с пользовательским соглашением http://www.mathnet.ru/rus/agreement

Параметры загрузки:

IP: 54.224 .135 .184

26 апреля 2023 г., 06:19:26

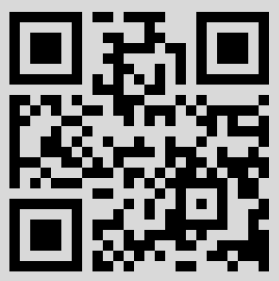




\section{МАТРИЧНЫЕ МОДЕЛИ ТЕКСТОВ. ИНТЕРПРЕТАЦИЯ МОДЕЛЕЙ \\ И ЭКСПЕРИМЕНТАЛЬНАЯ ВЕРИФИКАЦИЯ}

\section{(C) 2020 2. М.Г. Крейнес, В.М. Крейнес}

ООО "БАЗИСНЫЕ ТЕХНОЛОГИИ", Москва

mkrf@yandex.ru, elena.kreines@gmail.com

DOI: $10.20948 / \mathrm{mm}-2020-07-02$

Рассмотрена интерпретация матричных моделей текстов и формируемых на их основе моделей текстовых коллекций. Приведены примеры вычислительно построенных моделей текстовых коллекций, демонстрирующие содержательность результатов моделирования и возможности практического использования предложенных подходов. Описан оригинальный способ экспериментальной проверки приемлемости моделей текстов для решения задач смыслового поиска и анализа неструктурированной текстовой информации и приведены результаты соответствующего масштабного эксперимента.

Ключевые слова: тексты на естественных языках, текстовые коллекции, модели текстов, поиск и анализ информации, верификация моделей.

MATRIX TEXT MODELS. INTERPRETATION AND EXPERIMENTAL VERIFICATION OF MODELS

\section{M.G. Kreines, E.M. Kreines}

BaseTech Llc, Moscow

Interpretation of matrix models of texts and text collections is considered. Examples of computationally constructed models of text collections are presented. These examples demonstrate the richness of the simulation results and the possibilities of practical use of the proposed approaches. The original method of experimental verification of the acceptability of text models for solving problems of semantic search and analysis of unstructured text information is described, and the results of the corresponding largescale experiment are presented.

Key words: natural language texts, text collections, text models, text information retrieval, model verification.

\section{1. Введение}

Вычислительный содержательный анализ и поиск текстовой информации ориентированы на пользователя, которому математические методы дол- 
жны облегчить решение практических задач. Необходимыми условиями полезности результатов вычислений являются их интерпретируемость и правильность. Применимость тематических моделей (topic modeling) ограничена именно невысокой интерпретируемостью [1-3] части формируемых тематических групп и значений вероятности отнесения текста к соответствующим тематическим категориям [3]. Сама по себе интерпретируемость результатов вычислительного анализа и поиска текстов не может определить их правильность: естественный язык предоставляет настолько широкие возможности, что содержательную нелепость можно не только оправдать, но и возможно изобразить своеобразным открытием в семантике языка или в репрезентируемой текстом модели мира.

Для оценки правильности широко используются специализированные процедуры верификации, как правило, основанные на анализе тестовых коллекций (см., например, $[4,5])$, в рамках которых в качестве критерия правильности используется совпадение результатов вычислений и суждений экспертов. Таковы многочисленные соревнования в области анализа текстов, например, TREC (Text REtrieval Conference, Home Page - trec.nist.gov), SemEval (http://alt.qcri.org/semeval2018/), Российский семинар по оценке методов информационного поиска (РОМИП - romip.ru). Также в качестве инструмента верификации используются разнообразные тестовые коллекции, априори размеченные экспертами, например, Reuters-21578 (и Reuters22173), RCV1 (Reuters Corpus Volume 1) в соответствии с определенной системой рубрик. Распространен подход к оценке качества моделирования текстов по результатам вычислительной классификации по методу $K$ ближайших соседей для тестовых коллекций, классифицированных экспертами по определенным категориям (содержательным темам, положительным, отрицательным или нейтральным оценкам) $[5,6]$.

Слабость подходов к верификации, основанных на сравнении результатов с мнениями экспертов, определяется тем, что, как убедительно показано в [7], экспертные суждения не могут использоваться в качестве золотого стандарта для вычислительного анализа текстовой информации. Определенной альтернативой являются собрания текстов, имеющих перекрестные ссылки, которые позволяют установить содержательные связи текстов - база данных Medline, Википедия и др. Необходимо учитывать, что такие ссылки не являются абсолютной истиной: их формируют люди, исходя из собственных знаний и интересов. Поэтому внимание исследователей привлекает возможность предложить формальные не требующие привлечения экспертов показатели, характеризующие правильность и интерпретируемость результатов вычислительного анализа текстов и текстовых коллекций.

Для оценки интерпретируемости терминов, задающих тематические 
группы, также широко используется привлечение экспертов [2,3]. В качестве возможного критерия применяют оценивание содержательной однородности групп терминов, в частности, выявление экспертами включенных в состав групп случайно выбранных слов [1].

В рамках вероятностных подходов к описанию текстов на естественных языках и их коллекций распространены количественные показатели качества моделей, формулируемые в виде разнообразных статистических характеристик (перплексия и производные от нее показатели, поточечная взаимная информация слов как показатель содержательной связи слов [2, 3, $5,6])$. Успешно используется формирование требований к характеристикам тематических моделей в терминах регуляризаторов при решении некорректных задач тематического моделирования [8]. Для оценки интерпретируемости моделей текстовых коллекций используются показатели, определяемые непосредственно в ходе решения задачи тематического моделирования: число слов, при наличии которых условная вероятность темы выше пороговой (так называемый размер ядра темы), оценка суммы условных вероятностей слов для данной темы, представляющих тематическую группу (т.н. чистота темы), оценка математического ожидания условной вероятности темы при наличии слова из группы слов, связанных с темой (т.н. контрастность темы) (см., например, $[1,9])$. Подход к оценке качества тематических моделей, базирующийся на вычислении семантической однородности (когерентности) представляющих тематическую группу терминов предложен в [1-3] как замена экспертной оценки содержательности. Здесь критерий семантической однородности темы зависит от числа текстов, в которых рядом или в ближайшей окрестности друг от друга встретились два слова темы. Экспериментальные данные показывают весьма высокую корреляцию экспертных оценок и значений вычислимых характеристик [1-3].

В этой статье мы приводим примеры интерпретации и верификацию моделей текстов и текстовых коллекций, введенных в работах $[10,11]$. В разд.2 рассмотрена интерпретация моделей текстовых коллекций, формируемых на основании матричных моделей текстов, приведены примеры рассчитанных моделей и их интерпретация для различных по характеру коллекций текстов. В разд.3 предложен оригинальный способ верификации моделей, основанный на сравнении результатов категоризации масштабных коллекций текстов и их авторских аннотаций с использованием моделей текстов и коллекции. Приведены результаты соответствующего эксперимента с сотнями тысяч русскоязычных научных статей. Разд.4 содержит подмножества тематически сходных журналов, определенные при использовании представленных в [11, разд.4] моделей и алгоритмов, подтверждаю- 
щие правильность и интерпретируемость формируемых моделей. Здесь каждый журнал рассматривался как коллекция опубликованных в нем статей. В разд.5 представлены модели однородных тематических групп, полученных при кластеризации коллекции русскоязычных газетных текстов 1996-2003 годов, в которые входит слово "клетка", демонстрирующие правильность и интерпретируемость матричных моделей текстов и сформированной на их основе модели содержательного сходства текстов.

\section{2. Иерархия моделей текстовых коллекций и интерпретация весовых коэффициентов их компонент}

Рассмотренная в наших предыдущих статьях $[10,11]$ последовательность формирования моделей текстов на естественных языках и их коллекций отражает содержательную иерархию моделей. Смысл и интерпретация весовых коэффициентов компонент моделей - слов, различны для разных типов моделей.

Вес слова в модели текста характеризует значимость слова для представления тематики и содержания текста в целом и не имеет вероятностной интерпретации. Значению единица соответствует максимальная значимость. Переход от матричной модели к векторной, учитывающий максимальный вес слова в матричной модели, позволяет при построении моделей текстовых коллекций учесть отмеченные в [10] особенности функциональной и статистической структуры естественных языков, когда содержание текста определяется совместным использованием редких и "обычных" слов.

Вес слова в простейшей модели текстовой коллекции характеризует суммарную значимость слова во всех текстах коллекции. В простейшей модели слова упорядочены по неубыванию величины суммарной значимости. Число текстов, в моделях которых слово встречается, определяет средний вес слова в коллекции (здесь уместно вспомнить про параметр IDF - Inverse Document Frequency). Значение среднего веса слов позволяет грубо выделить в простейшей модели множества "тяжелых" и "легких" слов. Значение этих слов для представления семантики коллекции различно. "Тяжелые" слова в простейшей модели определяют четко представленные в текстах коллекции темы. "Легкие" слова характерны для моделей большого числа документов коллекции и поэтому в определенной степени способны характеризовать коллекцию в целом. В терминологии тематического моделирования [9] это разделение слов модели аналогично выделению предметных и фоновых тем.

Примеры начальных фрагментов простейших моделей для коллекций публикаций в журнале Science, выделенных по времени опубликования, приведены в табл.1. Проанализирован массив всех публикаций от момента 
начала издания журнала до 1996 г. включительно (всего более 160 тыс. статей). Все тексты разбиты на коллекции по времени публикации: с 1880 г. по 1909 г. (24736 текстов), с 1910 г. по 1939 г. (27806 текстов), с 1940 г. по 1959 г. (20189 текстов), с 1960 г. по 1979 г. (43391 текстов), с 1980 г. по 1996 г. (42665 текстов). В качестве множества текстов, определяющих естественный язык, при вычислениях была использована предметно не ориентированная коллекция сообщений информационных агентств. В табл.1 приведены наиболее "весомые" слова из простейших моделей, соответствующих перечисленным коллекциям, также приводится число документов, в которых слово встречается.

Таблица 1. Примеры начальных фрагментов простейших моделей для коллекций материалов журнала Science, сгруппированных по времени публикации.

\begin{tabular}{|c|c|}
\hline $\begin{array}{c}\text { Годы пуб- } \\
\text { ликации }\end{array}$ & $\begin{array}{c}\text { Слова модели, упорядоченные по неубыванию суммарного веса в кол- } \\
\text { лекции, число документов, в которых слово встречается }\end{array}$ \\
\hline 1880-1909 & $\begin{array}{l}\text { Professor } 12499 \text { birds } 2974 \text { Academy } 4653 \text { plates } 3624 \text { lectures } 3525 \text { twen- } \\
\text { ty } 6482 \text { Museum } 4517 \text { inch } 3592 \text { publication } 5035 \text { etc } 6509 \text { Lake } 3172 \text { feet } \\
6338 \text { chapter } 2788 \text { text } 3279 \text { knowledge } 6074 \text { Survey } 4437 \text { map } 2772 \text { inves- } \\
\text { tigation } 6531 \text { practical } 4602 \text { institutions } 4393 \text { interesting } 7417 \text { rocks } 3691 \\
\text { River } 4141 \text { species } 6153 \text { object } 5571\end{array}$ \\
\hline 1910-1939 & $\begin{array}{l}\text { Professor } 13634 \text { scientific } 13904 \text { laboratory } 11984 \text { experiments } 9447 \text { Col- } \\
\text { lege } 11045 \text { species } 5757 \text { chemical } 7953 \text { medical } 8057 \text { Society } 10883 \text { Insti- } \\
\text { tute } 8318 \text { chemistry } 7636 \text { Medicine } 5825 \text { lectures } 4710 \text { Association } 9026 \\
\text { Academy } 5270\end{array}$ \\
\hline 1940-1959 & $\begin{array}{l}\text { Medicine } 5314 \text { Chicago } 4099 \text { compounds } 3526 \text { publication } 4226 \text { chapter } \\
2127 \text { Foundation } 4626 \text { Academy } 2961 \text { associate } 2715 \text { acid } 5029 \text { annual } \\
3890 \text { technical } 4201 \text { substances } 3757 \text { virus } 1332 \text { preparation } 4164 \text { strain } \\
2142 \text { awarded } 2209 \text { institutions } 3985 \text { ray } 2773 \text { plates } 2048 \text { procedure } 4042 \\
\text { meetings } 2221 \text { illustrated } 2550 \text { genetic } 2090\end{array}$ \\
\hline 1960 & $\begin{array}{l}\text { chapter } 4059 \text { federal } 5065 \text { illus } 5659 \text { nuclear } 6908 \text { genetic } 5489 \text { compounds } \\
6092 \text { techniques } 12044 \text { Medicine } 7371 \text { instrument } 5426 \text { reader } 6731 \text { cells } \\
12223 \text { Academic } 7592 \text { Chicago } 6028 \text { distribution } 8455 \text { Editor } 3862 \text { envi- } \\
\text { ronmental } 6124 \text { Circle } 4942 \text { brain } 4704 \text { editorial } 2533 \text { virus } 1972 \text { institu- } \\
\text { tions } 6579 \text { procedure } 9466 \text { Ed } 9633 \text { book } 9901\end{array}$ \\
\hline 1980-1996 & $\begin{array}{l}\text { researchers } 9470 \text { genetic } 7942 \text { federal } 5143 \text { Editor } 3204 \text { cells } 15518 \text { nucle- } \\
\text { ar } 6487 \text { Circle } 4963 \text { virus } 3841 \text { cancer } 5890 \text { receptor } 5202 \text { gene } 9122 \text { panel } \\
4509 \text { brain } 5305 \text { environmental } 6230 \text { signal } 7699 \text { expression } 6238 \text { budget } \\
4540 \text { Soviet } 2283 \text { illus } 3484 \text { project } 8576 \text { drug } 5284 \text { chapter } 2512 \text { aid } 4905 \\
\text { antibody } 4965 \text { editorial } 2311 \text { agencies } 6057\end{array}$ \\
\hline
\end{tabular}

Простейшая модель сама по себе не очень выразительна, хотя ее внимательный анализ позволяет сделать обоснованные выводы относительно общей тематики коллекции текстов. Сопоставление моделей для коллекций, соответствующих разным временным промежуткам, может выявить распространение новых тем. Приведенные фрагменты ясно говорят о научно-образо- 
вательной направленности текстов коллекций, о смещении интересов авторов и редакции от "общего природоведения" к конкретным результатам актуальных научных исследований и к проблематике организации и финансирования науки. Например, результаты и методики исследования мозга заняли значимое место в публикациях 1960-1979 гг. и 1980-1996 гг. В публикациях 1980-1996 гг. тяжелым оказывается слово "virus", а слово "cells" - легким, что наглядно демонстрирует известные тенденции развития наук о жизни.

Вес слова в адаптивной контекстной модели определяется контекстным весом слова и характеризует значимость слова для представления семантики текстовой коллекции в целом: слова с большим весом наиболее значимы - они маркируют самые значимые темы в рамках коллекции. Слова с небольшим весом определяют общие характеристики коллекции - маркируют отличия коллекции в целом от множества текстов, представляющих язык, на котором написаны тексты коллекции. Здесь также уместно вспомнить о предметных и фоновых темах и подчеркнуть, что вес слова в адаптивной контекстной модели не имеет вероятностной интерпретации.

Примеры адаптивных контекстных приближений моделей для коллекций публикаций в журнале Science представлены в табл.2. Здесь приведены результаты для тех же коллекций, что и в табл.1. В табл.2 приведены наиболее значимые ("весомые") слова из адаптивных контекстных приближений моделей соответствующих коллекций.

Среди наиболее значимых научных тем на основании данных, приведенных в табл.2, легко увидеть появление генетики и вирусологии (коллекция публикаций 1910-1929 гг.), рост популярности нейро-мышечных исследований (коллекция публикаций 1940-1959 гг.), исследований РНК (коллекция публикаций 1960-1979 гг.), СПИДа (коллекция публикаций 1980-1996 гг.). Видна роль NASA и ССCР в научных публикациях за период 1960-1996 гг. В публикациях 1910-1939 гг. очевидна роль научных наград "honorary; medal", в публикациях 1940-1959 гг. видна роль образовательных учреждений "elected; educational; dean". C 1960 г. в научных публикациях активно обсуждается роль государства ("Senate").

Сравнение моделей, представленных в табл.1 и 2, позволяет наглядно убедиться в высокой информативности и значительной ценности для интерпретации данных адаптивной контекстной модели, в возможностях этой модели выявить динамику изменений содержания текстовых коллекций. Обращает внимание небольшое число пересечений наиболее значимых слов моделей в табл.1, 2. Представленные в табл.2 слова, значимые для тематической категоризации текстов, относятся к категории "тяжелых", но встречают- 
ся в сравнительно небольшом числе текстов коллекций, поэтому, недобрав по сумме весов, не попали в табл.1, где ввиду ограниченного объема статьи приведены только начальные фрагменты простейших моделей соответствующих коллекций.

Таблица 2. Примеры начальных фрагментов адаптивных контекстных приближений моделей для коллекций материалов журнала Science, сгруппированных по времени публикации.

\begin{tabular}{|c|c|}
\hline $\begin{array}{l}\text { Годы } \\
\text { опублик. }\end{array}$ & $\begin{array}{c}\text { Слова, представляющие семантические детерминанты коллекции и упо- } \\
\text { рядоченные по неубыванию веса в модели коллекции }\end{array}$ \\
\hline 1880-1909 & $\begin{array}{l}\text { storm; cloud; seed; wire; instructor; railway; shell; tribes; bone; steam; stars; } \\
\text { psychology; eggs; catalogue; meetings; coal; wave; ray; angle; vessels; tube; } \\
\text { des; metal; compounds; marine; philosophy; Louis; sand; ice; forest; mathe- } \\
\text { matics; depth; gas; mental; organic; Medicine; session; Country; wind; Berlin; } \\
\text { insects; salt; sun; height; edition; vice; soil; electrical; stream; }\end{array}$ \\
\hline 1910-1939 & $\begin{array}{l}\text { virus; bone; crystal; coal; strain; alcohol; male; female; slides; sugar; map; me- } \\
\text { dium; genetic; fruit; root; edition; seed; marine; Surgeons; stream; eggs; in- } \\
\text { structor; metal; compounds; honorary; wave; Pacific; deposits; medal; Canada; } \\
\text { motion; tube; mine; psychology; membership; rocks; instrument; trees; chapter; } \\
\text { gift; error; insects; Lake; birds; glass; addressed; inch; }\end{array}$ \\
\hline $1940-1959$ & $\begin{array}{l}\text { nerve; slides; sugar; illus; muscle; seed; eggs; root; female; diet; birds; rubber; } \\
\text { chamber; crystal; medal; male; virus; inch; serum; marine; layer; liver; alcohol; } \\
\text { edition; fellowship; mice; formerly; exposure; AAAS; negative; patients; dose; } \\
\text { particles; vitamin; elected; educational; flow; dean; count; reader; Congress; } \\
\text { feeding; enzyme; text; fraction; session; psychology; solid; }\end{array}$ \\
\hline $1960-1979$ & $\begin{array}{l}\text { Senate; virus; edition; birds; RNA; nerve; Soviet; pollution; editorial; muscle; } \\
\text { panel; solar; soil; ocean; visual; mathematics; crystal; educational; rocks; se- } \\
\text { rum; assistant; session; budget; marine; female; patients; metal; chain; mice; } \\
\text { zone; signal; wave; teaching; dose; depth; plates; Editor; Academy; graduate; } \\
\text { presentation; chapter; membrane; clinical; strain; cancer; male; }\end{array}$ \\
\hline 1980-1996 & $\begin{array}{l}\text { Advertising; HIV; Senate; prize; weapons; FAX; cloud; bone; users; software; } \\
\text { Mars; therapy; NASA; Soviet; editorial; muscle; satellite; laser; chapter; chro- } \\
\text { mosome; climate; marine; infected; ice; neurons; solar; ocean; assistant; gradu- } \\
\text { ate; female; infection; zone; tumor; metal; mutant; organic; Editor; crystal; at- } \\
\text { oms; male; Chicago; illus; Japan; wave; lane; mutations }\end{array}$ \\
\hline
\end{tabular}

Структурированная контекстная модель текстовой коллекции дает общее представление о тематике и содержании коллекции и позволяет оценить тематическую принадлежность каждого текста к выявленным в ходе вычислительного построения модели тематическим группам. Вес слова в элементе структурированной контекстной модели коллекции характеризует значимость слова для представления тематики и содержания соответствующей элементу группы текстов и используется при вычислительной категоризации текстов коллекции. Как и другие весовые коэффициенты в наших моделях, вес слова в элементе структурированной контекстной модели не 
имеет вероятностной интерпретации. Небольшой набор слов с близкими к единице весами может служить легко интерпретируемым содержательным заголовком тематической группы. В целом слова - семантические детерминанты группы задают смысловое поле тематической групы, определяющее содержательное соответствие ("притяжение") текста к тематической группе. Стилистические детерминанты характерны для коллекции в целом, определяют общий контекст использования семантических детерминант для тематической группы. Они не позволяют надежно категоризовать тексты, т.к. общий контекст часто оказывается типичен для нескольких групп одновременно.

В табл.3 приведен словарный состав элементов структурированных контекстных моделей коллекций публикаций в журнале Science за период с 1980 г. по 1996 г. в сопоставлении с тематикой публикаций за период с 1960 г. по 1979 г. Тематически близкие группы помещены в одну строку табл.3. Строки упорядочены по числу публикаций, отнесенных к тематическим группам для коллекции 1980-1996 гг. В строках 2 и 6 этим тематическим группам соответствуют 3 и 2 тематических группы коллекции 19601979 гг. Для каждого слова приведен вес (значимость) для соответствующего элемента модели. Для каждого элемента модели указано число текстов, отнесенных к тематике, ассоциированной с данным элементом. Алгоритм категоризации допускает отнесение текста к трем тематическим группам одновременно. В среднем один текст отнесен несколько менее чем к двум группам.

Таблица 3. Структурированная контекстная модель коллекций публикаций в журнале Science за периоды с 1980 г. по 1996 г. и с 1960 г. по 1979 г.

\begin{tabular}{|c|c|c|}
\hline $\begin{array}{l}\Gamma \\
\mathrm{p} \\
\mathrm{y} \\
\Pi \\
\Pi \\
\mathrm{b}\end{array}$ & $\begin{array}{l}\text { Общее число текстов в группе, Сло- } \\
\text { варный состав элемента структуриро- } \\
\text { ванной контекстной модели (вес - зна- } \\
\text { чимость слова в группе), 1980-1996 гг. }\end{array}$ & $\begin{array}{l}\text { Общее число текстов в группе, Сло- } \\
\text { варный состав элемента структуриро- } \\
\text { ванной контекстной модели (вес - зна- } \\
\text { чимость слова в группе), 1960-1979 гг. }\end{array}$ \\
\hline 1 & 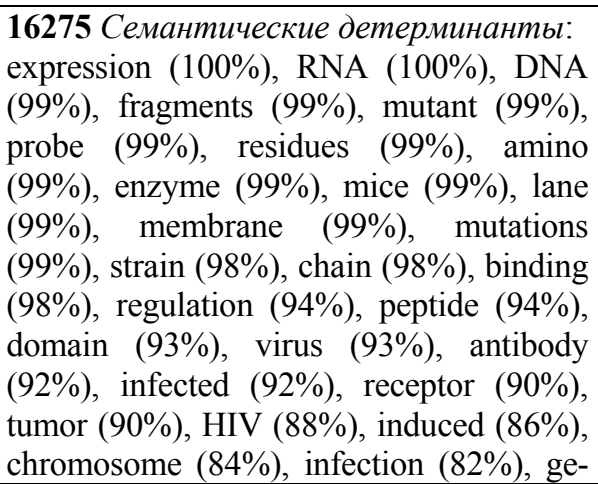 & $\begin{array}{l}\text { 12920 Семантические детерминанты: } \\
\text { isolated }(100 \%) \text {, medium }(100 \%) \text {, enzyme } \\
(100 \%) \text {, extract }(100 \%) \text {, synthesis }(100 \%) \text {, } \\
\text { ml }(100 \%) \text {, pH }(99 \%) \text { mg }(99 \%) \text {, RNA } \\
(99 \%) \text {, serum }(99 \%) \text {, mixture }(99 \%) \text {, virus } \\
(99 \%) \text {, strain }(99 \%) \text {, membrane }(99 \%) \text {, cul- } \\
\text { ture }(98 \%) \text {, mice }(98 \%) \text {, active }(97 \%) \text {, frac- } \\
\text { tion }(95 \%) \text {, chain }(77 \%) \text {, column (76\%), } \\
\text { substances }(76 \%) \text {, compounds }(70 \%) \text {, rats } \\
(70 \%) \text {, genetic }(62 \%) \text {, cancer }(62 \%) \text {, expo- } \\
\text { sure }(59 \%) \text {, Soc }(47 \%) \text {, content }(45 \%) \text { все- } \\
\text { го слов: } 28)\end{array}$ \\
\hline
\end{tabular}




\begin{tabular}{|c|c|c|}
\hline &  & $\begin{array}{l}\text { Стилистические детерминанть: acid } \\
(100 \%) \text {, presence }(99 \%) \text {, preparation }(99 \%) \text {, } \\
\text { concentration }(99 \%) \text {, cells }(99 \%) \text {, treated } \\
(80 \%) \text {, activity }(79 \%) \text {, weight }(76 \%) \text {, pro- } \\
\text { cedure }(64 \%) \text {, percent }(60 \%) \text {, indicated } \\
(55 \%) \text {, components }(55 \%) \text {, species }(50 \%) \text {, } \\
\text { grant (45\%), associated }(41 \%) \text {, complex } \\
(36 \%) \text { (всего слов: } 16)\end{array}$ \\
\hline 2 & $\begin{array}{l}11122 \text { Семантические детерминанты: } \\
\text { ocean }(99 \%) \text {, global }(97 \%) \text {, Mars }(96 \%) \text {, } \\
\text { earth }(94 \%) \text {, climate }(87 \%) \text {, ice }(86 \%) \text {, } \\
\text { cloud }(84 \%) \text {, solar }(80 \%) \text {, estimate }(78 \%) \text {, } \\
\text { zone }(78 \%) \text {, impact }(75 \%) \text {, satellite } \\
(70 \%) \text {, marine }(69 \%) \text {, carbon }(65 \%) \text {, ion } \\
(62 \%) \text {, environment }(60 \%) \text {, ray }(59 \%) \text {, } \\
\text { resolution (59\%), image (59\%), core } \\
(57 \%) \text {, origin }(56 \%) \text {, peak (56\%), NASA } \\
(56 \%) \text { computer (55\%), compounds } \\
(54 \%) \text {, distribution (53\%), wave (48\%), } \\
\text { environmental (48\%), flow (47\%), con- } \\
\text { clusion (46\%), frequency (42\%), elements } \\
\text { (42\%), error (37\%), components (35\%), } \\
\text { instrument (35\%), Circle (32\%), June } \\
\text { (30\%) (всего слов: } 37) \\
\text { Стилистические детерминанть: space } \\
(64 \%) \text {, techniques (55\%), model (55\%), } \\
\text { Сenter (48\%), proposed (30\%) (всего } \\
\text { слов: 5) }\end{array}$ & 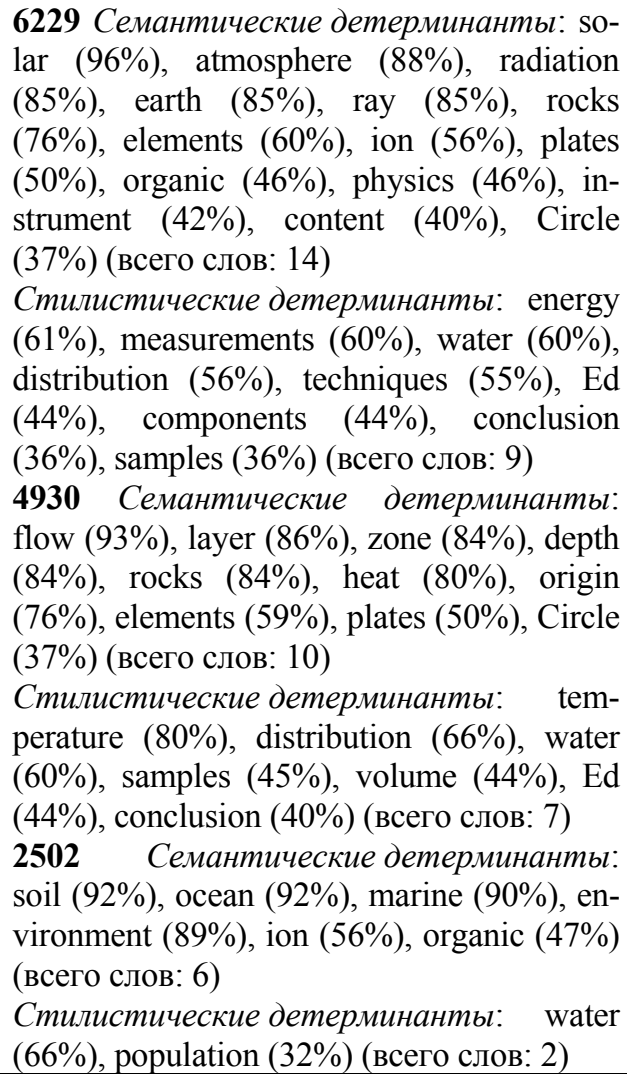 \\
\hline 3 & $\begin{array}{l}\text { 10426 Семантические детерминанть: } \\
\text { Senate (99\%), Congress (99\%), budget } \\
(99 \%) \text {, agencies }(99 \%) \text {, proposal }(99 \%) \text {, } \\
\text { funds }(99 \%) \text {, federal }(99 \%) \text {, policy }(99 \%) \text {, } \\
\text { project }(99 \%) \text {, facilities }(87 \%) \text {, Admin- } \\
\text { istration }(85 \%) \text {, Foundation }(79 \%) \text {, Acad- } \\
\text { emy }(77 \%) \text {, resources }(75 \%) \text {, weapons }\end{array}$ & $\begin{array}{l}\text { 12310 Семантические детерминанты: } \\
\text { Academy }(100 \%) \text {, social }(100 \%) \text {, committee } \\
(100 \%) \text {, education }(100 \%) \text {, budget }(100 \%) \text {, } \\
\text { associate }(100 \%) \text {, project }(100 \%) \text {, Congress } \\
(100 \%) \text {, agencies }(100 \%) \text {, federal }(100 \%) \text {, } \\
\text { resources }(100 \%) \text {, panel }(100 \%) \text {, education- } \\
\text { al }(100 \%) \text {, institutions }(100 \%) \text {, Senate }\end{array}$ \\
\hline
\end{tabular}




\begin{tabular}{|c|c|c|}
\hline & $\begin{array}{l}(73 \%) \text {, panel }(71 \%) \text {, graduate }(61 \%) \text {, So- } \\
\text { viet }(60 \%) \text {, basic }(59 \%) \text {, environmental } \\
(55 \%) \text {, prize }(47 \%) \text {, grant }(46 \%) \text {, NASA } \\
(45 \%) \text {, technical }(45 \%) \text {, lab }(45 \%) \text {, Aca- } \\
\text { demic }(42 \%) \text {, June }(40 \%) \text { (всего слов: } \\
27) \\
\text { Стилистические детерминантьл: } \\
\text { program }(70 \%) \text {, researchers }(66 \%) \text { (всего } \\
\text { слов: } 2)\end{array}$ & 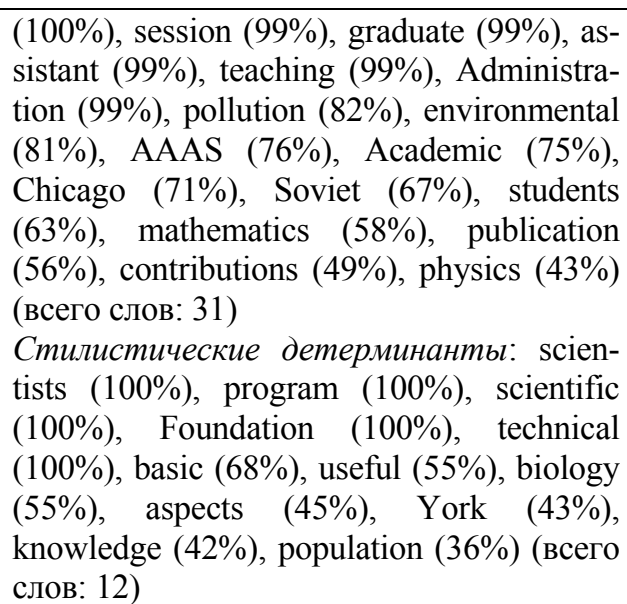 \\
\hline 4 &  & $\begin{array}{l}7123 \text { Семантические детерминанты: } \\
\text { curve (97\%), constant }(85 \%) \text {, frequency } \\
(83 \%) \text {, signal }(83 \%) \text {, cm }(82 \%) \text {, wave } \\
(78 \%) \text {, peak }(75 \%) \text {, intervals }(71 \%) \text {, error } \\
(66 \%) \text {, visual }(65 \%) \text {, cycle }(52 \%) \text {, physics } \\
(41 \%) \text { (всего слов: } 12) \\
\text { Стилистические детерминанть: meas- } \\
\text { urements }(79 \%) \text {, distribution }(64 \%) \text {, behav- } \\
\text { ior }(62 \%) \text {, characteristic }(55 \%) \text {, techniques } \\
(54 \%) \text {, associated }(40 \%) \text {, conclusion }(34 \%) \text {, } \\
\text { complex }(28 \%) \text { (всего слов: } 8)\end{array}$ \\
\hline 5 & $\begin{array}{l}8701 \text { Семантические детерминанты: } \\
\text { heat }(87 \%) \text {, particles }(83 \%) \text {, layer }(80 \%) \text {, } \\
\text { carbon }(68 \%) \text {, ion }(62 \%) \text {, wave }(62 \%) \text {, ray } \\
(59 \%) \text {, compounds }(59 \%) \text {, resolution } \\
(59 \%) \text {, image }(59 \%) \text {, peak }(56 \%) \text {, laser } \\
(56 \%) \text {, environment }(55 \%) \text {, computer } \\
(55 \%) \text {, organic }(51 \%) \text {, distribution }(50 \%) \text {, } \\
\text { core }(49 \%) \text {, flow }(47 \%) \text {, conclusion } \\
(46 \%) \text {, frequency }(42 \%) \text {, error }(37 \%) \text {, be- } \\
\text { havior (35\%), instrument }(35 \%) \text {, nuclear } \\
(32 \%)(\text { всего слов: } 24) \\
\text { Стилистические детерминанть: } \\
\text { еnеrgy (71\%), space }(64 \%) \text {, techniques } \\
(60 \%), \text { тодеl }(55 \%) \text {, Center }(48 \%) \text { (всего } \\
\text { слов: } 5)\end{array}$ & $\begin{array}{l}7853 \text { Семантические детерминанты: } \\
\text { heat }(99 \%) \text {, solid }(99 \%) \text {, gas }(90 \%) \text {, metal } \\
(90 \%) \text {, ray }(90 \%) \text {, crystal }(90 \%) \text {, particles } \\
(90 \%) \text {, radiation }(84 \%) \text {, liquid }(74 \%) \text {, nu- } \\
\text { clear }(71 \%) \text {, ion }(66 \%) \text {, elements }(60 \%) \text {, or- } \\
\text { ganic }(57 \%) \text {, plates }(52 \%) \text {, Circle }(44 \%) \text {, } \\
\text { content }(40 \%) \text { (всего слов: } 16) \\
\text { Cтилистические детерминанть: tem- } \\
\text { perature }(78 \%) \text {, measurements }(74 \%) \text {, tech- } \\
\text { niques }(64 \%) \text {, energy }(62 \%) \text {, volume }(44 \%) \text {, } \\
\text { Ed (44\%), components (44\%), complex } \\
(27 \%)(\text { всего слов: } 8)\end{array}$ \\
\hline 6 & 7851 Семантические детерминанть: & минанты: \\
\hline
\end{tabular}




\begin{tabular}{|c|c|c|}
\hline & $\begin{array}{l}\text { cancer }(99 \%) \text {, therapy }(99 \%) \text {, HIV }(99 \%) \text {, } \\
\text { clinical }(99 \%) \text {, patients }(99 \%) \text {, infection } \\
(99 \%) \text {, bone }(98 \%) \text {, tumor }(97 \%) \text {, Medi- } \\
\text { cine }(95 \%) \text {, virus }(95 \%) \text {, infected }(95 \%) \text {, } \\
\text { mice }(83 \%) \text {, drug }(79 \%) \text {, dose }(79 \%) \text {, aid } \\
(78 \%) \text {, brain }(75 \%) \text {, NIH }(70 \%) \text {, exposure } \\
(66 \%) \text {, muscle }(51 \%) \text {, lab }(45 \%) \text { (всего } \\
\text { слов: } 20) \\
\text { Стилистические детерминанть: } \\
\text { human }(98 \%), \text { Institute }(71 \%), \text { researchers } \\
(66 \%)(\text { всего слов: } 3)\end{array}$ & $\begin{array}{l}\text { brain }(95 \%) \text {, rats }(83 \%) \text {, muscle }(83 \%) \text {, } \\
\text { nerve }(80 \%) \text {, patients }(79 \%) \text {, dose }(79 \%) \text {, } \\
\text { drug }(76 \%) \text {, genetic }(62 \%) \text {, cancer }(59 \%) \text {, } \\
\text { exposure }(57 \%) \text { (всего слов: } 10) \\
\text { Стилистические детерминанты: animals } \\
(82 \%) \text {, response }(71 \%) \text {, percent }(60 \%) \text {, be- } \\
\text { havior }(52 \%) \text {, procedure }(52 \%) \text {, indicated } \\
(45 \%) \text {, grant (43\%), associated }(32 \%) \text { (все- } \\
\text { го слов: } 8) \\
\mathbf{2 1 1 8 ~ С е м а н т и ч е с к и е ~ д е т е р м и н а н т ь : ~} \\
\text { clinical (81\%), Меdicine (81\%), genetic } \\
(62 \%) \text {, сапсег (53\%) (всего слов: } 4) \\
\text { Стилистические детерминанть: biology } \\
(49 \%) \text { (всего слов: } 1)\end{array}$ \\
\hline 7 & $\begin{array}{l}5702 \text { Семантические детерминанты: } \\
\text { Editor (98\%), FAX (97\%), editorial } \\
(96 \%) \text {, Chicago }(93 \%) \text {, Advertising } \\
(89 \%) \text {, associate }(89 \%) \text {, assistant }(88 \%) \text {, } \\
\text { reader }(85 \%) \text {, AAAS }(81 \%) \text {, social }(71 \%) \text {, } \\
\text { publication }(70 \%) \text {, graduate }(62 \%) \text {, basic } \\
(59 \%) \text {, prize }(57 \%) \text {, Academic }(51 \%) \text {, } \\
\text { technical (46\%), users (37\%), grant } \\
(37 \%) \text {, software }(34 \%) \text { (всего слов: } 19)\end{array}$ & 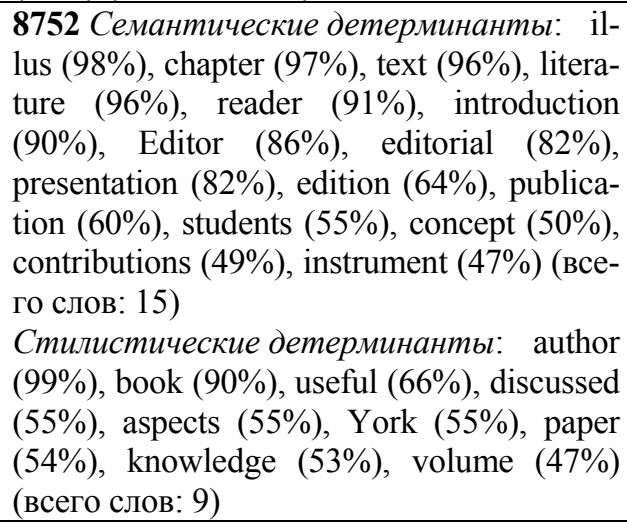 \\
\hline 8 & $\begin{array}{l}\text { 5297 Семантические детерминанты: } \\
\text { News }(99 \%) \text {, assistant }(99 \%) \text {, institutions } \\
(98 \%) \text {, comment }(96 \%) \text {, education }(91 \%) \text {, } \\
\text { associate }(90 \%) \text {, Advertising }(88 \%) \text {, edito- } \\
\text { rial }(86 \%) \text {, FAX }(82 \%) \text {, Japan }(80 \%) \text {, } \\
\text { Foundation }(70 \%) \text {, graduate }(63 \%) \text {, basic } \\
(59 \%) \text {, technical }(40 \%) \text {, grant }(39 \%) \text {, lab } \\
(36 \%) \text { (всего слов: } 16) \\
\text { Стилистические детерминанть: } \\
\text { scientists }(77 \%), \text { researchers }(66 \%) \text { (всего } \\
\text { слов: } 2)\end{array}$ & \\
\hline 9 & $\begin{array}{l}1951 \text { Семантические детерминанты: } \\
\text { illus (93\%), chapter }(93 \%) \text {, Academic } \\
(56 \%) \text { (всего слов: } 3) \\
\text { Стилистические детерминанть: paper } \\
(86 \%) \text {, York }(65 \%) \text { (всего слов: } 2)\end{array}$ & $\begin{array}{l}8752 \text { Семантические детерминанты: : il- } \\
\text { lus }(98 \%) \text {, chapter }(97 \%) \text {, text }(96 \%) \text {, litera- } \\
\text { ture }(96 \%) \text {, reader }(91 \%) \text {, introduction } \\
(90 \%) \text {, Editor }(86 \%) \text {, editorial }(82 \%) \text {, } \\
\text { presentation }(82 \%) \text {, edition }(64 \%) \text {, publica- } \\
\text { tion }(60 \%) \text {, students }(55 \%) \text {, concept }(50 \%) \text {, } \\
\text { contributions }(49 \%) \text {, instrument }(47 \%) \text { (все- } \\
\text { го слов: } 15) \\
\text { Стилистические детерминанть: author } \\
(99 \%) \text {, book }(90 \%) \text {, useful }(66 \%) \text {, discussed } \\
(55 \%) \text {, aspects }(55 \%) \text {, York }(55 \%) \text {, paper }\end{array}$ \\
\hline
\end{tabular}




\begin{tabular}{|c|c|c|}
\hline & & $\begin{array}{l}\text { (54\%), knowledge }(53 \%) \text {, volume }(47 \%) \\
\text { (всего слов: } 9)\end{array}$ \\
\hline 10 & $\begin{array}{l}\text { 1001 Семантические детерминанть: } \\
\text { female }(82 \%) \text {, male }(82 \%) \text {, behavior } \\
(38 \%) \text { (всего слов: } 3)\end{array}$ & $\begin{array}{l}2703 \text { Семантические детерминанты: } \\
\text { male }(86 \%) \text {, female }(86 \%) \text {, birds }(57 \%) \text {, } \\
\text { exposure }(46 \%) \text { (всего слов: } 4) \\
\text { Стилистические детерминанты: percent } \\
(60 \%) \text {, procedure }(52 \%) \text {, species }(48 \%) \text {, be- } \\
\text { havior }(47 \%) \text {, indicated }(45 \%) \text {, population } \\
(42 \%) \text {, grant }(41 \%) \text { (всего слов: } 7)\end{array}$ \\
\hline
\end{tabular}

Приведенные в табл.3 модели выявляют основные тематические направления публикаций за периоды 1960-1979гг. и 1980-1996 гг.: исследования в области молекулярной биологии и генетики (гр. 1), исследования окружающей среды, космоса и работы в области рационального природопользования (гр. 2), проблемы организации и финансирования научных исследований (гр. 3), исследования в области физики, химии, материаловедения, лазерной техники и энергетики (гр. 4,5$)$, медицинские исследования (прежде всего в области онкологии, инфекционных заболеваний, нейробиологии, нейромышечных исследований, биологических моделей - гр. 6), информационные и рекламные материалы об академической жизни, научных конференциях, научных наградах, научном оборудовании и о программном обеспечении (гр. 7), обзоры академической жизни и сведения о назначениях и вакансиях (гр. 8), обзоры книжных изданий (гр. 9), исследования популяций и поведения (гр. 10). Тексты, попавшие в группы 7-9 в подавляющем большинстве случаев одновременно отнесены и к другим тематическим группам, определяющим содержательную направленность публикаций. Модели показывают естественную для развития науки преемственность тематики исследований. Одновременно приведенные модели демонстрируют различия, характерные для выделенных временных интервалов. В 1980-1996 гг. исследования в области молекулярной медицины и генетики стали ориентироваться на проблемы медицины. Большое внимание в теоретической и практической медицине занял СПИД. Исследования Земли объединились с космическими исследованиями, с изучением океана, проблемами климатологии и экологии (для публикаций 1960-1979 гг. данной тематике соответствуют три тематические группы). Обзоры академической жизни и сведения о назначениях и вакансиях выделились в отдельную тематическую группу. Отметим, что омоним "volume" попал в стилистические детерминанты групп 5 и 9 в соответствии со своими значениями "объем" и "том", "illus" в гр. 9 - это сокращение "illustration". Сравнение с данными, приведенными в [12], показывает серьезные различия в формируемых моделях и в возмож- 
ностях их интерпретации. Впрочем, часть различий (напр., отсутствие в нашей модели озоновой тематики как существенной для всей коллекции) может быть связана с неполным совпадением проанализированных текстовых коллекций (1980-1996 гг. в наших экспериментах и 1990-1999 гг. в [12]).

Табл.4 и 5 из следующего раздела также демонстрируют хорошую интерпретируемость адаптивной контекстной и структурированной контекстной моделей, построенных по коллекции русскоязычных научных статей.

Практически интересным приложением структурированных контекстных моделей является возможность получения количественных оценок тематического сходства текстовых коллекций. Две модели оценивания тематического сходства текстовых коллекций приведены в нашей предыдущей статье. Примеры их использования для выявления тематически близких научных журналов приведены в [13] и в четвертом разделе настоящей статьи. Экспертный анализ вычислительно сформированных групп тематически близких русскоязычных научных журналов для 1500 журналов, каждый из которых представлен не менее чем 100 статьями, показал достоверность и высокое качество такой группировки.

\section{3. Тексты и аннотации: верификация матричной модели текста}

Задачи верификации моделей текстов и текстовых коллекций весьма сложны. Мнение эксперта не может быть надежно использовано в качестве "золотого стандарта" [7], а результаты вычислительного анализа текстов благодаря возможности их содержательной интерпретации часто выглядят разумными и обоснованными, по существу таковыми не являясь.

Методы проверки и сравнения разнообразных моделей текстов, текстовых коллекций и их применения в задачах поиска и анализа неструктурированной текстовой информации, не связанные с прямым привлечением экспертов для оценки качества моделей, используют масштабные коллекции текстов, в которых имеется априорная категоризация или определена система ссылок (например, Википедия, WordNet, PubMed) для выявления содержательно близких текстов [2]. Данные таких коллекций рассматриваются как материал для оценки качества моделей вычислительного анализа текстов. Структура и свойства представленных в данной статье моделей таковы, что их можно верифицировать без привлечения подобных ресурсов.

В качестве средства верификации мы предложили использовать сопоставление результатов вычислительной тематической категоризации масштабной коллекции научных текстов и их аннотаций, выполненной на базе матричной модели текстов и формируемой на их основе системы моделей текстовых коллекций. Высокую долю статей и соответствующих им аннота- 
ций, отнесенных к одной и той же тематической группе структурированной контекстной модели, естественно трактовать как показатель работоспособности моделей рассматриваемого класса.

Вычислительный эксперимент проводился с коллекцией текстов, состоящей из 922231 русскоязычных научных статей (общее число словоупотреблений - 1852000 865), опубликованных в период 2011-2015 гг., полные тексты которых представлены на информационном ресурсе Электронная научная библиотека (elibrary.ru). Предварительная обработка текстов не производилась, не выполнялись токинезация и исправление опечаток, возникших в результате распознавания текстов. Число различных слов (лемм), вошедших в тексты (общий объем словаря коллекции), составило почти 2500000 и включало в себя слова русского языка, научные термины, географические и административные названия, имена, фамилии, иноязычные слова (литературные ссылки), опечатки, ошибки распознавания. Для 381659 статей Электронной научной библиотекой были предоставлены тексты авторских или редакционных аннотаций с привязкой статья - аннотация. Для всех статей и аннотаций построены матричные модели. В модели текстов вошло почти 700 тысяч слов. По матричным моделям статей вычислительно сформированы адаптивное контекстное приближение модели коллекции 922231 русскоязычных научных статей (соответствующие данные не приведены из-за ограниченного объема статьи) и структурированная контекстная модель (табл.4), в соответствии с которой выполнена категоризация статей и аннотаций (их отнесение к элементам структурированной модели на основании количественного показателя содержательного соответствия текста тематической группе, см. [11]). Напомним, что для категоризации документов коллекции используются только семантические детерминанты коллекции. Представляют интерес суммарные данные о числе словоупотреблений слов адаптивного контекстного приближения модели в коллекции. Всего словоупотреблений 709 слов семантических детерминант 234582270 - 12.66\% от общего числа словоупотреблений в коллекции, в среднем $0.0176 \%$ общего числа словоупотреблений на одно слово. Из них словоупотреблений 130 слов с очень высокой значимостью, которые выделяются в модели по величине весового коэффициента слова в адаптивной контекстной модели, $23563034-1.27 \%$, в среднем $0.0098 \%$ общего числа словоупотреблений на одно слово. Всего словоупотреблений 217 слов стилистических детерминант, включая маркеры коллекции в целом: 246702289 - $13.32 \%$ - в среднем $0.061 \%$ общего числа словоупотреблений на одно слово. Всего словоупотреблений 7 слов маркеров коллекции в целом (маркера- 
ми коллекции оказались следующие слова: условия; система; вид; различный; образом; основной; время) 21926695 - 1.18\%, в среднем $0.168 \%$ общего числа словоупотреблений на одно слово.

Таблица 4. Категоризация статей и аннотаций Научной электронной библиотеки за 20112015 гг., основанная на структурированной контекстной модели коллекции.

\begin{tabular}{|c|c|c|c|c|}
\hline гр. & $\begin{array}{c}\text { число } \\
\text { слов в } \\
\text { группе }\end{array}$ & $\begin{array}{l}\text { число текстов, } \\
\text { отнес. к группе }\end{array}$ & 5 наиболее весомых слов группы & $\begin{array}{c}\text { интерпретация } \\
\text { тематики группы }\end{array}$ \\
\hline 1 & 204 & 261307 & $\begin{array}{l}\text { инвестиций, инвестиционных, сектора, } \\
\text { финансирования, капитала }\end{array}$ & экономика \\
\hline 2 & 153 & 225082 & $\begin{array}{l}\text { вещи, реальности, философских, случай- } \\
\text { но, искусства }\end{array}$ & $\begin{array}{c}\text { гуманитарные } \\
\text { науки }\end{array}$ \\
\hline 3 & 112 & 199567 & $\begin{array}{l}\text { крови, препаратов, клинических, терапии, } \\
\text { заболевания }\end{array}$ & медицина \\
\hline 4 & 111 & 166727 & $\begin{array}{l}\text { педагогов, учащихся, учителя, воспита- } \\
\text { ния, заведений }\end{array}$ & $\begin{array}{c}\text { проблемы образо- } \\
\text { вания } \\
\end{array}$ \\
\hline 5 & 75 & 148635 & $\begin{array}{l}\text { излучения, алгоритм, переменных, урав- } \\
\text { нения, параметров }\end{array}$ & точные науки \\
\hline 6 & 69 & 97014 & $\begin{array}{l}\text { исполнения, обязанности, юридических, } \\
\text { закона, актов }\end{array}$ & $\begin{array}{c}\text { юридические } \\
\text { науки }\end{array}$ \\
\hline 7 & 43 & 104944 & излучения, нм, камеры, мкм, угол & физика \\
\hline 8 & 39 & 77678 & $\begin{array}{l}\text { Восточной, Северной, Востока, Южной, } \\
\text { Северо }\end{array}$ & регионоведение \\
\hline 9 & 31 & 81143 & камеры, нм, атомов, мкм, излучения & техн. физика \\
\hline 10 & 26 & 72111 & моль, ионов, молекул, атомов, веществ & химия \\
\hline 11 & 17 & 22515 & $\begin{array}{l}\text { Украины, Союза, Германии, Европы, ев- } \\
\text { ропейских }\end{array}$ & $\begin{array}{c}\text { международные } \\
\text { отношения }\end{array}$ \\
\hline 12 & 17 & 28707 & $\begin{array}{l}\text { строительных, автомобилей, транспорт- } \\
\text { ных, транспорта, строительства }\end{array}$ & строительство \\
\hline 13 & 17 & 29264 & сорта, молочной, корма, кг, количество & животноводство \\
\hline 14 & 13 & 18340 & $\begin{array}{l}\text { заместитель, профессор, доктор, докладе, } \\
\text { конференции }\end{array}$ & научная жизнь \\
\hline 15 & 13 & 17316 & $\begin{array}{l}\text { техники, машин, оборудования, техниче- } \\
\text { ских, завод }\end{array}$ & $\begin{array}{c}\text { промышленное } \\
\text { производство }\end{array}$ \\
\hline 16 & 11 & 10552 & гор, черной, белого, Красной, земли & география \\
\hline 17 & 11 & 12955 & $\begin{array}{l}\text { опасных, опасности, угрозы, последст- } \\
\text { вий, конфликта }\end{array}$ & $\begin{array}{c}\text { проблемы без- } \\
\text { опасности }\end{array}$ \\
\hline 18 & 10 & 15590 & $\begin{array}{l}\text { фронта, советской, войны, военной, пар- } \\
\text { тии }\end{array}$ & $\begin{array}{c}\text { история Отечест- } \\
\text { венной войны }\end{array}$ \\
\hline 19 & 9 & 22149 & $\begin{array}{l}\text { добычи, нефти, промышленности, про- } \\
\text { мышленных, технологических }\end{array}$ & $\begin{array}{c}\text { добыча полезных } \\
\text { ископаемых }\end{array}$ \\
\hline 20 & 8 & 22408 & площади, га, природных, участков, почвы & агрономия \\
\hline 27 & 6 & 9695 & $\begin{array}{l}\text { компьютера, пользователя, цифровой, } \\
\text { компьютерной, программного }\end{array}$ & информатика \\
\hline 30 & 5 & 9859 & $\begin{array}{l}\text { канала, сигнала, передачи, устройства, } \\
\text { использования }\end{array}$ & связь \\
\hline 31 & 5 & 7180 & $\begin{array}{l}\text { энергии, тепловой, ядерных, энергетичес- } \\
\text { ких, потока }\end{array}$ & энергетика \\
\hline 32 & 6 & 3656 & $\begin{array}{l}\text { конструкции, сопротивления, корпуса, } \\
\text { материала, испытаний }\end{array}$ & инженерное дело \\
\hline
\end{tabular}


В табл.4 приведены первые 5 наиболее "весомых" слов для каждого элемента структурированной контекстной модели коллекции полнотекстовых статей. Всего получено 79 тематических групп. Тематические группы упорядочены по числу слов, отнесенных к группе. Анализ табл.4 демонстрирует отличную интерпретируемость приведенных "заголовков" тематических групп. Группы, следующие за 20-й группой, главным образом конкретизируют тематику предыдущих групп. Поэтому для сокращения объема статьи большая их часть не приведена.

В вычислительном эксперименте, ориентированном на проверку правильности моделей, реализованы два режима категоризации: тексту сопоставляется три тематических группы в соответствии с тремя большими значениями показателя содержательного соответствия модели ("притяжения") текста и модели тематической группы или единственная тематическая группа, соответствующая максимальному значению показателя содержательного соответствия. Из приведенных в табл.5 данных видно, что число статей, для которых не удалось найти подходящую тематическую группу, составило менее $1 \%$ общего числа статей. Первые 20 тематических групп определили категоризацию практически всех категоризованных статей и аннотаций. При категоризации по максимальному значению для 21-й группы число отнесенных к ней статей и аннотаций падает больше, чем на порядок по сравнению с числом соответствующих текстов, отнесенных к первой группе. Значение показателя содержательного соответствия характеризует уверенность в результатах категоризации. "Притяжение" менее 0.1 свидетельствует о некоторой неопределенности. Поэтому показатель среднего по коллекции значения "притяжения" говорит об определенности результатов категоризации. Приведенные в табл.5 значения показывают высокую уверенность в результатах категоризации для полных текстов и для аннотаций.

Основной целью эксперимента была проверка отнесения статьи и аннотации к одной и той же тематической группе, определенной структурированной контекстной моделью коллекции. Данные, представленные в табл.5, демонстрируют работоспособность приведенной системы моделей.

Для оценки полученных результатов сопоставим их с известными из литературы показателями правильности распространенных подходов к моделированию и анализу текстов на естественных языках. Удобным источником данных являются [5,6], где приведены результаты сравнения различных моделей текстов и характеристик содержательной близости текстов по величине доли ошибочно классифицированных документов по методу $K$ ближайших соседей для ряда размеченных экспертами коллекций. $80 \%$ текстов 
каждой коллекции использовали как обучающую выборку и $20 \%$ использовали как тестовую. В эксперименте были исследованы следующие восемь моделей представления текстов: частотный словарь текста (мешок слов) - вектор в пространстве размерности словаря анализируемой коллекции [14], модель TF/IDF [15], модель BM25 Okapi, обобщающая модель TF/IDF [16], модель латентного семантического анализа [17], модель тематического моделирования [18], модель MSDA [19], модель CCG, обобщающая моделирование текста как распределения слов и модель тематического моделирования [20], модель расстояния между словами (word mover's distance - WMD) и производная от нее модель расстояния между документами, использующая в качестве базовых знаний модель типа word2vec, обученную на выборке текстов, насчитывающей миллиарды слов [5]. Для моделей мешка слов $T F / I D F$, BM25 Okapi и WMD обучение использовано только для выбора оптимального числа соседей (от 1 до 19), по которому выполнялась классификация.

Таблица 5. Данные, характеризующие категоризацию статей и аннотаций Научной электронной библиотеки за 2011-2015 гг., основанную на структурированной контекстной модели коллекции.

\begin{tabular}{|c|c|c|c|}
\hline & Характеристика категоризации & $\begin{array}{c}\text { Коллекция } \\
\text { текстов }\end{array}$ & $\begin{array}{l}\text { Коллекция } \\
\text { аннотаций }\end{array}$ \\
\hline 1 & $\begin{array}{l}\text { Средний показатель “притяжения” (текст мо- } \\
\text { жет быть отнесен к нескольким категориям) }\end{array}$ & 0.53 & 0.303 \\
\hline 2 & $\begin{array}{l}\text { Средний максимальный показатель “притя- } \\
\text { жения” }\end{array}$ & 0.64 & 0.40 \\
\hline 3 & Число категоризованных документов & 914306 & 381659 \\
\hline 4 & В том числе с притяжением более 0.10 & 899036 & 341377 \\
\hline 5 & В том числе с притяжением более 0.20 & 879744 & 304769 \\
\hline 6 & $\begin{array}{l}\text { Число пар текст/аннотация, попавших в одну } \\
\text { категорию }\end{array}$ & \multicolumn{2}{|c|}{$323657-84.8 \%$} \\
\hline 7 & $\begin{array}{l}\text { Число пар текст/аннотация, попавших в одну ка- } \\
\text { тегорию по максимальному показателю близости }\end{array}$ & \multicolumn{2}{|c|}{$228387-59.8 \%$} \\
\hline 8 & $\begin{array}{l}\text { Число пар текст/аннотация, попавших в одну } \\
\text { категорию для первых } 9 \text { категорий }\end{array}$ & \multicolumn{2}{|c|}{288780} \\
\hline 9 & $\begin{array}{l}\text { Число пар текст/аннотация, попавших в одну } \\
\text { категорию для первых } 20 \text { категорий }\end{array}$ & \multicolumn{2}{|c|}{311815} \\
\hline 10 & $\begin{array}{l}\text { Число пар текст/аннотация, попавших в одну } \\
\text { категорию по максимальному показателю бли- } \\
\text { зости для первых } 9 \text { категорий }\end{array}$ & \multicolumn{2}{|c|}{$\begin{array}{c}209334-74 \% \text { от общего числа } \\
\text { аннотаций в этих группах }\end{array}$} \\
\hline 11 & $\begin{array}{l}\text { Число пар текст/аннотация, попавших в одну } \\
\text { категорию по максимальному показателю бли- } \\
\text { зости для первых } 20 \text { категорий }\end{array}$ & \multicolumn{2}{|c|}{$\begin{array}{c}222973-68 \% \text { от общего числа } \\
\text { аннотаций в этих группах }\end{array}$} \\
\hline
\end{tabular}

Несмотря на использование процедуры обучения, малое число классов и небольшой объем текстов для коллекций TWITTER (2176 твитов, разме- 
ченных как положительный, отрицательный или нейтральный), RECIPE (3059 кулинарных рецептов, размеченных по 15 регионам происхождения), OSHUMED (3999 рефератов медицинских статей, размеченных по группам 10 сердечно-сосудистых заболеваний) доля ошибок варьировалась от $30 \%$ до 66\%, для коллекции 20NEWS (11293 новостных сообщений, размеченных по 20 категориям) - от $27 \%$ до $58 \%$. Причем классические модели BM25 Okapi, TF/IDF и мешок слов показали худшие результаты (доля ошибок близка к 60\%). Для коллекций CLASSIC (4965 предложений из научных статей, размеченных по наименованиям 4 издателей) и REUTERS (5485 новостных сообщений, размеченных по 8 категориям) модели BM25 Okapi, $T F / I D F$ и модель мешка слов показали ошибки около и более $30 \%$ (для последней коллекции модель мешка слов продемонстрировала 14\% ошибок). Значительно меньше ошибок (от 3\% до 20\%) остальные модели смогли обеспечить для коллекций BBC sports (517 текстов, 5 классов, соответствующих видам спорта), CLASSIC, REUTERS и AMAZON (5600 обзоров товаров, размеченных по 4 типам - книги, DVD, электроника, кухонное оборудование), что объясняется высокой эффективностью процедур обучения при малом числе классов и небольшом числе коротких текстов.

К сожалению, прямое сопоставление наших моделей с приведенными результатами невозможно из-за априори фиксированных классификационных схем рассмотренных в $[5,6]$ тестовых коллекций. Действительно, в наших моделях тематические группы анализируемой коллекции не предполагаются априори заданными, но формируются в ходе анализа текстов коллекции адаптивно к ее свойствам. Общий уровень ошибок (наибольший интерес для сравнения представляют результаты классификации коллекций OSHUMED, RECIPE и 20NEWS ввиду большего, чем в других коллекциях числа рассматриваемых классов и большего объема словаря текстов) в сопоставлении с оценками правильности, полученными в вычислительных экспериментах с матричными моделями текстов, свидетельствуют о достоинствах и практической применимости наших моделей.

\section{4. Примеры тематического подобия коллекций публикаций в научных журналах}

Приводимые ниже примеры вычислительных оценок тематического подобия коллекций публикаций в научных журналах, сформированные в соответствии с [11, разд.4], демонстрируют возможности практического применения матричных моделей неструктурированных текстов на естественных языках для поиска сопоставимых по тематике акторов научной деятельности. Выявление сопоставимых по тематике акторов научной деятель- 
ности - необходимый шаг для процедур ранжирования акторов по разнообразным показателям их эффективности или качества.

После каждого выделенного жирным шрифтом журнала приведены два, наиболее близкие ему по тематике, после каждого из них указано значение соответствующего показателя тематического подобия.

Вестник Московского университета. Серия 2: Химия: Сорбционные и хроматографические процессы; 0.895; Журнал физической химии; 0.791; Успехи химии: Журнал органической химии; 0.759; Нефтехимия; 0.619; Вестник Казанского государственного технического университета им. А.Н. Туполева: Вестник Московского авиационного института; 0.774; Наука и образование: электронное научно-техническое издание; 0.770 ; Известия ТИНРО (Тихоокеанского научно-исследовательского рыбохозяйственного центра): Вопросы рыболовства; 0.718; Известия Иркутского государственного университета. Серия: Биология. Экология; 0.692; Вестник Нижегородского университета им. Н.И. Лобачевского. Серия: Социальные науки: Ученые записки Забайкальского государственного университета. Серия: Философия, социология, культурология, социальная работа; 0.753; Известия Российского государственного педагогического университета им. А.И. Герцена; 0.734; Детские инфекции: Педиатрическая фармакология; 0.902; Вопросы практической педиатрии; 0.898; Зоотехния: Молочное и мясное скотоводство; 0.823; Проблемы биологии продуктивных животных; 0.659; Агрохимия: Агрохимический вестник; 0.677; Доклады Российской академии сельскохозяйственных наук; 0.609; Проблемы современной экономики: Современные проблемы экономического и социального развития; 0.853; Вестник экономической интеграции; 0.834; Вопросы философии: Вестник Московского университета. Серия 7: Философия; 0.828; Вестник Российского университета дружбы народов. Серия: Философия; 0.804; Автоматика и телемеханика: Дифференциальные уравнения; 0.691; Вестник Воронежского государственного университета. Серия: Системный анализ и информационные технологии; 0.662; Известия Российской академии наук. Серия литературы и языка: Искусствознание; 0.911; Русская речь; 0.867; Музыка и время: Музыковедение; 0.945; Филология и человек: Известия Саратовского университета. Новая серия. Серия: Филология. Журналистика; 0.942; Русская речь; 0.898; Неорганические материалы: Расплавы; 0.903; Физика и химия стекла; 0.878; Теплофизика высоких температур: Физико-химическая кинетика в газовой динамике; 0.902; Известия Российской академии наук. Серия физическая; 0.787; Физикохимическая кинетика в газовой динамике: Теплофизика высоких темпе- 
ратур; 0.902; Известия высших учебных заведений. Физика; 0.788; Банковское дело: Финансовые исследования; 0.934; Деньги и кредит; 0.896; Финансы и кредит: Финансовая жизнь; 0.913; Финансовые исследования; 0.886; Российское предпринимательство: Экономические и гуманитарные науки; 0.936; Финансовая аналитика: проблемы и решения; 0.908; Кубанский научный медицинский вестник: Владикавказский медико-биологический вестник; 0.953; Вестник Санкт-Петербургского университета. Серия 11: Медицина; 0.949; Психология обучения: Социальная педагогика; 0.937; Муниципальное образование: инновации и эксперимент; 0.806; Вестник Московского государственного областного университета. Серия: Педагогика: Вектор науки Тольяттинского государственного университета. Серия: Педагогика, психология; 0.907; Педагогическое образование в России; 0.890; Хирургия позвоночника: Травматология и ортопедия России; 0.928; Гений ортопедии; 0.925; Вестник Российского университета дружбы народов. Серия: Медицина: Волгоградский научно-медицинский журнал; 0.903; Бюллетень Восточно-Сибирского научного центра Сибирского отделения Российской академии медицинских наук; 0.883 ; Педиатрическая фармакология: Вопросы практической педиатрии; 0.942; Российский вестник перинатологии и педиатрии; 0.913; Анналы клинической и экспериментальной неврологии: Мануальная терапия; 0.957; Сборник научных трудов Всероссийского научно-исследовательского института овцеводства и козоводства: Свиноводство; 0.593; Достижения науки и техники АПК; 0.587; Авиакосмическое приборостроение: Известия высших учебных заведений. Приборостроение; 0.779; Приборы и системы. Управление, контроль, диагностика; 0.741.

\section{5. Результаты кластеризации коллекции газетных статей}

В данном разделе представлены результаты кластеризаци, коллекции русскоязычных газетных текстов 1996-2003 гг., в которые входит слово "клетка" (всего 14728 текстов из общего числа 2470157 текстов коллекции). Кластеризация выполнена вычислительно описанным в нашей работе [11, разд.2] алгоритмом. Выявленные кластеры демонстрируют наличие разнообразных значений и четко различимых смысловых контекстов слова "клетка". Приведены данные по первым 30 группам, упорядоченным по невозрастанию числа текстов в группах, по пять ключевых слов для каждой группы и общее число текстов, отнесенных к группе. Всего в 30 групп, данные о которых представлены, вошли 9059 текстов.

Все документы (14728 док.): гр.1 (3813 док.): клетки, организм, заболевание, лечения, болезнь; гр.2 (801 док.): зоопарк, клетку, зверей, цирке, жи- 
вотных; гр.3 (788 док.): клетки, травм, водитель, грудной, происшествия; гр.4 (611 док.): подъездов, лестничных, жильцов, коммунального, жилищно; гр.5 (365 док.): лестничные, пожаров, пожарную, клетки, возгорание; гр.6 (346 док.): собак, животных, клетках, кошки; гр.7 (332 док.): модой, одежды, тканей, костюмов, цвет; гр.8 (251 док.): кожей, Косметические, крем, лучей, организмом; гр.9 (225 док.): ребенка, родителями, детей, беременность, малышей; гр.10 (219 док.): сперматозоиды, мужских, яйцеклетки, оплодотворение, клетки; гр.11 (187 док.): подсудимых, приговора, суда, адвокаты, потерпевшая; гр.12 (170 док.): спектакли, Театр, актера, пьесе, сценой; гр.13 (126 док.): передний, автомобиль, заднего, водителя, кузовом; гр.14 (94 док.): фильме, кино, снимать, актер, съемки; гр.15 (92 док.): космического, космонавты, космоса, полеты, эксперименты; гр.16 (90 док.): учителем, школа, ученики, педагогов, урока; гр.17 (88 док.): лестничной, двери, ворах, домушнику, квартиры; гр.18 (77 док.): лестничной, выстрелы, пистолета, клетке, киллер; гр.19 (72 док.): дохода, вычеты, декларации, заполняется, указывается; гр.20 (71 док.): Нобелевские, премии, лауреаты, клетках, медицины; гр.21 (70 док.): шахматистов, Каспарова, шахматные, гроссмейстеров, шахматы; гр.22 (53 док.): птицефабрик, птицу, яиц, мяса, кормить; гр.23 (51 док.): наук, физико, институты, молекул, академик; гр.24 (51 док.): дома, квартире, жильцов, лестничные, жилья; гр.25 (49 док.): олимпийский, чемпионаты, спорту, соревнований, медали; гр.26 (48 док.): спектакль, опере, сцене, оперного, Гергиев; гр.27 (48 док.): Локомотива, игроков, Спартак, тренера, лиге; гр.28 (46 док.): мамонта, клонированием, клетка, клонировать, слонихи; гр.29 (46 док.): Букер, Азольский, премия, жюри, писатели; гр.30 (42 док.): тюрьме, заключенным, камеры, Бутырку, тюремный.

В больших группах ключевые слова показывают разнообразную тематическую направленность текстов, в которых встретилось слово "клетка". Легко идентифицировать соответствующую различной тематике семантику слова: медицинскую проблематику (биологическая клетка), жизнь животных (клетка для содержания животных), подверженная травмам анатомическая структура (грудная клетка), проблемы ЖКХ и преступности (лестничная клетка), вопросы моды (клетка как элемент дизайна одежды), проблемы репродукции и семьи (биологическая клетка в конкретной предметной области), судебную тематику (клетка для подсудимого), проблематика театра (человек в клетке - почти что термин в театральных рецензиях, характеризующий высокую степень изоляции индивидуума), вопросы заполнения налоговых деклараций (клетка - фрагмент бланка), общественное признание научных достижений (клетка как объект успешных медико-био- 
логических исследований, как образ внутренней или внешней изоляции ученого), шахматы (клетка на шахматной доске), клетка как оборудование в промышленном и домашнем птицеводстве. Ряд небольших по числу текстов групп связан с конкретными событиями, например, с желанием клонировать мамонтов, или с конкретной тематикой, в которой "клетка" упоминается, но не играет существенной роли (кино, космос, спорт, школа). Следует отметить, что в последних группах часто встречается словосочетание "нервная клетка", которую следует беречь, можно испортить и т.п., содержательно не имеющее отношения ни к медицине, ни к биологии.

\section{6. Заключение}

Приведенные данные вычислительных экспериментов показывают высокое качество матричных моделей текстов и формируемых на их основе моделей текстовых коллекций. Интерпретируемость моделей и результаты, полученные при верификации моделей, демонстрируют практическую применимость рассмотренных моделей. Предложенный способ верификации моделей текстов и текстовых коллекций, использующий категоризацию текстов и их аннотаций, может применяться на основе масштабных коллекций научных текстов для оценки качества альтернативных вариантов моделей текстов и текстовых коллекций.

Авторы благодарны Научной электронной библиотеке Elibrary.ru за представление текстов русскоязычных научных статей и их аннотаций.

\section{СПИСОК ЛИТЕРАТУРЫ}

1. D. Mimno, H. Wallach, E. Talley, M. Leenders, A. McCallum. Optimizing semantic coherence in topic models // Proc. of Conf. on Empirical Methods in Natural Language, Edinburgh, Scotland, UK, July 27-31, 2011, p.262-272.

2. D. Newman, J.H. Lau, K. Grieser, T. Baldwin. Automatic evaluation of topic coherence // Human Language Technologies: Annual Conf. of the North American Chapter of the ACL. - Los Angeles, California, 2010, p.100-108.

3. D. Newman, Y. Noh, E. Talley, S. Karimi S., T. Baldwin. Evaluating topic models for digital libraries // Proc. of 10th Annual Joint Conf. on Digital Libraries. - New York: ACM, 2010, p.215-224.

4. P. Bojanowski, E. Grave, A. Joulin, T. Mikolov. Enriching word vectors with subword information // arXiv:1607.04606v1 [cs.CL]. Preprint of Cornell Univ. Series Math. Cornell, 2016, $12 \mathrm{p}$.

5. M.J. Kusner, Y. Sun, N.I. Kolkin, K.Q. Weinberger. From Word Embeddings To Document Distances / Proc. of 32nd Inter. Conf. on Machine Learning, Lille, France, 2015. W\&CP, v.37, p.957-966.

6. G. Huang, Ch. Guo, M.J. Kusner, Y. Sun, K.Q. Weinberger, F. Sha. Supervised Word Mover's Distance / 30th Conf. on Neural Inform. Proc. Syst., Barcelona, Spain, 2016, 9 p. 
7. T. Saracevič. Effects of inconsistent relevance judgments on information retrieval test results: A historical perspective // LIBRARY TRENDS, 2008, v.56, №4, p.763-783.

8. К.В. Воронциов. Аддитивная регуляризация тематических моделей коллекций текстовых документов // Доклады РАН, 2014, т.456, №3, с.268-271.

K.V. Vorontsov. Additive Regularization for Topic Models of Text Collections // Doklady Mathematics, 2014, v.89, № 3, p.301-304.

9. К.В. Воронцов, А.А. Потапенко. Аддитивная регуляризация тематических моделей // http://www.machinelearning.ru/wiki/images/2/28/Voron14mlj-rus.pdf. 2014, c.1-22.

K.V. Vorontsov, A.A. Potapenko. Additivnaia reguliarizatsiia tematicheskikh modelei // http://www.machinelearning.ru/wiki/images/2/28/Voron14mlj-rus.pdf. 2014, p.1-22.

10. М.Г. Крейнес, Е.М. Крейнес. Матричные модели текстов. Модели текстов и содержательное сходство текстов // Математич. моделирование, 2020, т.32, №1, с.31-49.

M.G. Kreines, E.M. Kreines. Matrix text models. Text models and similarity of text contents // MM\&CS, 2020, v.12, №5.

11. М.Г. Крейнес, Е.M. Крейнес. Матричные модели текстов. Модели текстовых коллекций // Математическое моделирование, 2020, т.32, №2, с.37-57.

M.G. Kreines, E.M. Kreines. Matrix text models. Text corpora models // MM\&CS, 2020, v.12, №5.

12. D. Blei, J. Lafferty. A correlated topic model of Science // Annals of Applied Statistics, 2007, v.1, p.17-35.

13. М.Г. Крейнес, Е.М. Крейнес. Модель управления выбором референтных коллекций для объективной оценки качества научно-технических публикаций по библиометрическим и наукометрическим показателям // Изв. РАН. ТИСУ, 2016, т.5, с.73-89.

M.G. Kreines, E.M. Kreines. The control model for the selection of reference collections providing the impartial assessment of the quality of scientific and technological publications by using bibliometric and scientometric indicators // Journal of Computer and Systems Sciences International, v.55, №5, p.750-766.

14. W.B. Frakes, R. Baeza-Yates. Information Retrieval: Data Structures and Algorithms. New Jersey: Prentice Hall, Englewood Cliffs, 1992, 630 p.

15. G. Salton, C. Buckley. Term-weighting approaches in automatic text retrieval // Inform. Processing \& Management, 1988, v.24, №5, p.513-523.

16. S.E. Robertson, S. Walker, M. Beaulieu. Experimentation as a way of life: Okapi at TREC. // Inform. Processing \& Management, 2000, v.36, p.95-108.

17. S. Deerwester, S.T. Dumais, G.W. Furnas, T.K. Landauer, R. Harshman. Indexing by Latent Semantic Analysis // J. of American Soc. for Inform. Sci., 1990, v.41, №6, p.391-407.

18. D.M. Blei. Probabilistic topic models // Communications of the ACM, 2012, v.55, №4, p.77-84.

19. M. Chen, Z. Xu, K.Q. Weinberger, F. Sha. Marginalized denoising autoencoders for domain adaptation. In ICML, $2012 / /$ arXiv:1206.4683 [cs.LG]. Preprint of Cornell University. Series Math. Cornell, 2012, 8 p.

20. A. Perina, N. Jojic, M. Bicego, A. Truski. Documents as multiple overlapping windows into grids of counts. NIPS, 2013, p.10-18.

Поступила в редакцию 16.05.2019

После доработки 16.05.2019

Принята к публикации 01.07.2019 